\title{
Filming Space/Mapping Reality in Chinese Independent Documentary Films
}

Judith Pernin

\section{CpenEdition}

\section{Journals}

Electronic version

URL: http://journals.openedition.org/chinaperspectives/5052

DOI: 10.4000/chinaperspectives.5052

ISSN: 1996-4617

Publisher

Centre d'étude français sur la Chine contemporaine

Printed version

Date of publication: 21 April 2010

ISSN: 2070-3449

\section{Electronic reference}

Judith Pernin, « Filming Space/Mapping Reality in Chinese Independent Documentary Films », China Perspectives [Online], 2010/1 | 2010, Online since 01 April 2013, connection on 28 October 2019. URL http://journals.openedition.org/chinaperspectives/5052 ; DOI : 10.4000/chinaperspectives.5052 


\section{Filming Space/Mapping Reality}

in Chinese Independent

Documentary Films

IUDITH PERNIN

This article is a general attempt to sum up and challenge some of the issues the notion of Space raises when in contact with the Chinese independent documentary film movement. I will focus my analysis on how this concept influences the choice of topics, the roles it plays during the shooting process and how the representation of space in these films is linked to the emergence of a new documentary aesthetic and practice.

$\mathrm{S}$ ince the beginning of the 1990s, independent documentary filmmakers have explored the Chinese territory and made visible people and places rarely seen or even taken into consideration by traditional media. This movement has grown in a specific space often described as an intermediate realm between the public and the private sphere, and has dedicated itself to the recording of China's margins, both geographical and social.

As an attempt to reflect on society, documentary cinema deals with people and their living conditions. But the choice of a topic or of a main "character" is often related to another underlying but nonetheless very significant choice: the filmed space. The famous documentarist Frederick Wiseman has built all his filmography around this very concept: each of his films is the description of institutional spaces (jail, hospital, museum, etc.) and the way people interact in them. ${ }^{(2)}$ In this type of film, and also in Chinese independent documentaries, places and topics are intimately related. While space plays a strong role in defining the scope of the film's subjects, its mode of representation also conveys the filmmaker's opinion about the event as well as his aesthetic preferences. ${ }^{(3)}$ In the case of Chinese independent documentaries, not only have the filmmakers shed light on certain places, populations, and contemporary issues, they have also reconfigured the aesthetics and the practice of documentary film by questioning the medium and setting a number of new rules. Among those are the rejection of television norms for documentary films and the adoption of a style close to direct cin- ema, which includes a new approach of both subject matter and filmed counterparts. By focusing on ordinary people and giving them a space for speech, by developing their topics in full-length movies, and by rejecting any kind of didactic purpose (such as no explanation through voiceover) they aim at the standards of auteur cinema, and at a certain degree of "truth," as well.

The emergence of this movement outside the realm of the film industry and television questions the status of documen-

1. This essay is the development of three different papers presented respectively at the Symposium "Between Public and Private: a Space for Independent Chinese Cinema" (organised by the HKIFF and the CEFC in April 2009), at the Baptist University conference "Hong Kong Documentary Film, the Regional Context and Theoretical Perspectives" (May 2009), and at the Spaces of Asian Cinema conference in UC Davis (October 2009). I would like to thank the anonymous evaluators for their critiques and Alexis Lycas for his proofreading and comments.

2. For further readings on Wiseman and his use of space, see Bill Nichols, "Fred Wiseman's Documentaries: Theory and Structure," Film Quarterly, Vol. 31, No. 3 (Spring, 1978), pp. 15-28; Francois Niney, "Fictions du réel selon Wiseman, Rouch, Cassavetes," in L'épreuve du réel à l'écran: essai sur le principe de réalité documentaire, Brussels, De Boeck Université, 2002, pp. 147-157.

3. The concept of space in cinema indeed raises numerous problematics that have been theorised by various authors such as André Bazin (Qu'est ce que le cinéma, Paris, Cerf 2002), Noël Burch (Praxis du cinéma, Paris, Gallimard, Coll. Folio, 1986), or Pascal Bonitzer (Le champ aveugle, Paris, Cahiers du cinéma, 1982). André Gardies (L'espace au cinéma, Paris, Méridiens-Klincksieck, 1993) offers a useful summary and further theorisation on this topic. This article's discussion on space draws partly from André Gardies' definitions ("espace filmé," "espace représenté," "espace narratif," "espace diégétique," "espace du spectateur"). These categories, used by Gardies for fiction film, are suited to our study of documentary films. On space in documentary films, we can refer to Bill Nichols' classic: Representing Reality: Issues and Concepts in Documentary, Bloomington, Indiana University Press, 1991, and especially "Axiographics, ethical space in documentary films" (pp. 76-105), although Nichols's "ethical" approach and terminology will not be used here. 
tary film in China, both as a visual work - its aesthetics, meaning, and role - and as a cultural product - its economy, audience, and distribution.

In most countries, the distribution of documentary cinema is more difficult than it is for fiction films, as screening opportunities and dedicated institutions are relatively scarce. These films usually remain a product for television broadcast, even though they sometimes get screening opportunities in regular movie theatres. In the case of Chinese independent documentary films, as they are drawn away from the normal dissemination channels from the very start, and as auteur documentary film is a largely neglected cinematic form in China, it becomes especially hard to show them. However, filmmakers and film critics have taken into account these difficulties and the particular status of Chinese independent cinema to create the conditions for these movies to exist in a specific sphere, even though this space is a rather narrow one. The independent festivals, archives, cafés, and events that allow them to exist demonstrate the prominence of physical space as a means of disseminating movies, even in the Internet age.

Given the importance of the notion of space in its relationship to cinema in general and to this cinematography in particular, I would like to sum up and challenge some of the issues space raises when in contact with Chinese independent documentaries. This paper aims at taking space as an entry point to study, both on the level of the films and on the scale of the "New Documentary Movement," the many ways geographic data merge with the independent practice of recording and showing reality in China. I will focus on the influence of space on the choice of topics, the roles space plays during the shooting process, and the relationships it induces between the filmmaker, the filmed counterparts, and the viewer. The representation of space is a way for the director to assert aesthetical choices and to express his views on reality; this point will be developed in the film analysis throughout this essay. In my concluding remarks, I will attempt to demonstrate that this new production of meaning and the aesthetics it presupposes induce and go hand in hand with the necessity to produce an alternative cinematographic realm. While in the beginning the independent status of these films and their aesthetics prevented them from accessing public screenings, dooming them to marginalisation and invisibility, the creation of specific screening venues at the turn of the twenty-first century has enabled them to gain access to cinematographic space. The difficulties of screening these films have indeed pushed the "New Documentary Movement" to play a role in the evolution of social space in terms of participating in the elaboration of minjian spaces. This analysis is based on a choice of Chinese independent documentaries that are well-known enough to be familiar to the reader, and diverse enough to represent different trends within this movement.

\section{Space as a source of inspira- tion: Human geography and choice of topics in Chinese in- dependent documentaries}

The range of subjects covered by Chinese independent documentaries is quite broad; there is some unity among them, however. The first independent filmmakers focused a great deal on marginal populations. Several movies were made on China's boundaries such as Tibet or the north-eastern provinces, and show the local population through a totally different approach from the one used in TV documentaries. ${ }^{(4)}$ Some took the form of road movies, or, more accurately, railway movies in the case of Ning Ying's film Railway of Hope (Xiwang zhi lü, 2002), which depicts the seasonal travel of female workers in Xinjiang. Other directors focused on urban marginal populations such as avant-garde artists, floating populations, and beggars, but also prostitutes and drug addicts. The marginality seen in early Chinese independent documentaries is not only that of the filmed counterparts, but is also often the marginality felt by the directors themselves, who could, at least in the beginning, define themselves as liumang, ${ }^{(5)}$ sharing in that respect the same "floating" identity as the protagonists. Progressively extending their interest to "ordinary people" (workers, students, or farmers), the filmmakers usually show them at a decisive moment of their life - as when Ai Xiaoming films the dispossession of peasant land in Taishicun (2005), or when Wang Bing films the collapse of an industrial area in West of the tracks (Tiexiqu, 2003).

Many of these films focus on expropriation problems, travel, seclusion, or immigration, on urbanisation and the destruction of rural or industrial landscapes, as if the main interest of the filmmakers relied upon space-related questions. What

4. We could cite works by Ji Dan, Sha Qing (Gongbu's Happy Life, Gongbu de Xingfu Shenghuo, 1999), or Duan Jinchuan (No. 16 Barkhor South Street, Bakuo Nanjie 16 hao, 1997) for Tibet.

5. This word means both "vagrant" and "hooligan." Geremie Barmé explains that this word can also relate to a larger concept of "embryonic alternative culture" formed by wandering artists (mangliu yishujia) and petty thieves (See "Wang Shuo and Liumang (Hooligan) Culture," The Australian Journal of Chinese Affairs, No. 28, July 1992, pp. 23-64). Given their lack of recognition and their nomadic way of life in the 1980s and early 1990s, many Chinese unofficial artists could easily see themselves as belonging to the most marginal stratum of society. 
one often sees in these films are persons whose fate is determined by the space they belong to. Beyond the primary focus on the social strata of the protagonists, people's relation to space is often the underlying theme of the movies: the chosen topics reveal that most of the issues people face are linked to the place they occupy or are unable to occupy, territories they lose or pass through. Generally speaking, the marginality or triviality of the protagonists depends on or is revealed by the space in which they live. Hence the numerous movies made on migrant workers doomed to ceaseless travel, ${ }^{(6)}$ on people dispossessed of their homes or farmland, ${ }^{(7)}$ or on the elderly secluded in their homes. ${ }^{(8)}$ Space indeed appears as a source of numerous social problems or conflicts in contemporary China, since possessing a rural or urban hukou and consequently being affiliated to a certain area can determine one's social position and activity. The traces left by contemporary history on Chinese territory are also an important inspiration to many filmmakers, who use socialist architecture or monumental remnants of the Maoist era to reveal the fact that spatial management is also a way to conceptualise social relationships. ${ }^{(9)}$ History can also manifest itself in a less visible way but nonetheless be deeply felt by the population, for instance when conflicts around the use of peasant lands unearth former collectivisation and lead to unresolvable legal and economical problems (Ai Xiaoming, Taishicun, 2005). Geographical disparities and spatial distribution of working opportunities in China are also at the core of many films focusing on migration issues (Ning Ying, The Railway of Hope, 2002; Zhou Hao, Houjie, 2002). One of the particularities of these documentaries is to show how social categories and issues are linked to social space and ultimately to geographical space, or to space as a physicality. The changes affecting rural areas through urbanisation, the destruction of traditional neighbourhoods, and the gentrification of formerly impoverished areas are abundantly shown in these films. These images reveal the evolution of space as a social construction, and as a hierarchical tool used to separate people by activity, social status, age, or ethnic background. They display the inextricable relationship between geographical space and social realities, as well as the historical layers hidden behind places. By showing how people's lives and fates are subordinated to the place they occupy, these films reveal how spatial problematics have a hold on people's lives in China and how people confront them. But this deep concern of the social and historical dimension of space is also a way to give marginal or ordinary places a cinematic status through formal research. As we will see, a lot of these films show empty space, wastelands, suburbs, and waiting spaces, and record the destruction of urban or industrial landscapes in a very thorough and aesthetical way.

\section{spatial constraints and mode of shooting}

The aesthetics of Chinese independent documentaries was historically formed as a critique of television formats used on state channels before the 1990s. Even though different trends exist in this movement, the films even today bear characteristics roughly defining direct cinema. These documentaries are filmed "on the spot"; they usually don't use archival footage, voiceovers, or additional sounds. The sounds we hear are produced in the actual shooting space and are not added during post-production; consequently, there is no disjunction between image and sound, giving the shots spatial unity and homogeneity. Conversely, in ordinary television documentaries, space is often heterogeneous: the sound doesn't necessary belong to the image on screen and it is instead composed of several layers (for instance, additional music and sound effects, or voiceover commentary). The site of the event is also usually shrunk to its minimum signifying size in order to give the action or the interview the best efficiency. We know where the scene is being filmed either from captions, the display of descriptive shots, or landscape elements easy to identify, but the space shown only bears an illustrative or a dramatic function related to the progress of an event. In independent documentaries, on the other hand, long landscape shots with or without any people carrying out actions are displayed in their full length, giving space more than just a background value. The shooting usually consists of following the filmed counterparts without disturbing the event, the filmmaker having then to adapt himself to the action, and also to the place where it is happening. The spatial constraints of the shooting are thus integrated into the matter of the movie itself. These documentaries seem to be moulded around the space where they

6. Wu Wenguang's corpus of films, from Bumming in Beijing (1990) - portraying young provincial artists settled in Beijing - to Your Name is Outlander (Ni de Mingzi Jiao Waidiren), 2008, can actually be understood as a extended study on migration, immigration (At Home in the World - Si Hai wei Jia, 1995), rural exodus (Dancing with Migrant Workers - He Mingong Tiaowu, 2002), wandering (Jianghu, 1999), and their causes (see the film series Villager Documentaries, Cunmin Jilupian, 2005, and My Village in 2007, Wo de Cunzi 2007 Nian, 2008).

7. Cao Fei, Ou Ning, Zhang Jinli, Meishi Street (Meishi Jie, 2006), Jiang Zhi, The Nail (Dingzi, 2008), Ai Xiaoming, Taishicun (2005).

8. Yang Lina, Old Men (Laotou, 1999), Li Xiaofeng, Jia Kai, My Last Secret (Wo Zuihou de Mimi, 2007), Ji Dan, Dream in an Empty City (Kong Cheng yi Meng, 2008).

9. West of the Tracks (2001) by Wang Bing and Sanlidong (2006) by Lin Xin remain so far the best examples of this kind of movie. 
have been filmed, as they transcribe its asperities and particularities in an almost topographic manner. Documentaries shot in exiguous private places reveal the lack of space through odd angles, whereas films in open public spaces have to deal with street noise and scale differences between the landscape and the people. Filmmakers also take spatial constraints into account during the editing process. To recreate the scenes, they usually choose to follow a slow-paced chronological order, instead of fragmenting the event (and therefore the space) in a series of actions as in the case in mainstream documentaries. Whether they are shot in private settings or in public, the common point of these documentaries is to preserve and expose the spatial constraints of the shooting spot in order to describe the context in which filmmaker and filmed subjects evolve.

In the movie Petition (Shangfang, Zhao Liang, 2009), part of the shooting is carried out in the tiny rooms of the petitioners, who live temporarily in Beijing in order to voice their protests to the central government. Zhao Liang records his encounters with them and the conversations between the protagonists sitting in a corner or on the bottom of a bunk bed, his camera struggling to find enough light and distance to film them. As a result of this confined environment, most of the indoor shots are dark close-ups facing the people from below while they are standing. The quality of these images - somewhat "poor" by normal television standards - is not considered an obstacle to their use. They are kept in the movie as a record of the spatial and social constraints imposed on these people. Another form of spatial constraint, this time generated by public spaces, was captured by Jia Zhangke in his film In Public (Gonggong Changsuo), made in 2001. The movie starts in a suburban train station of $\mathrm{Da}$ tong and follows an itinerary bringing the camera into all kinds of public spaces: a bus station, a bus, a restaurant, a pool room, and finally a dance hall.

What we see on screen in the first half of the movie are people waiting for means of locomotion or for their vehicle to come to a halt and arrive at a destination. When people stop travelling in the second half of the film, it's the camera that moves, bringing us from one scene to another with a tracking shot. Just like when we go through a public space, on our own, our eyes linger on one or two people we find fascinating for a moment, and we imagine their stories. They are our companions through this journey in public space, some "familiar strangers" ${ }^{(1)}$ with whom we will probably never come into contact. For instance, the woman at the bus stop meeting a friend, or the strange man in the wheelchair wearing dark glasses. Although the sequences are constructed around
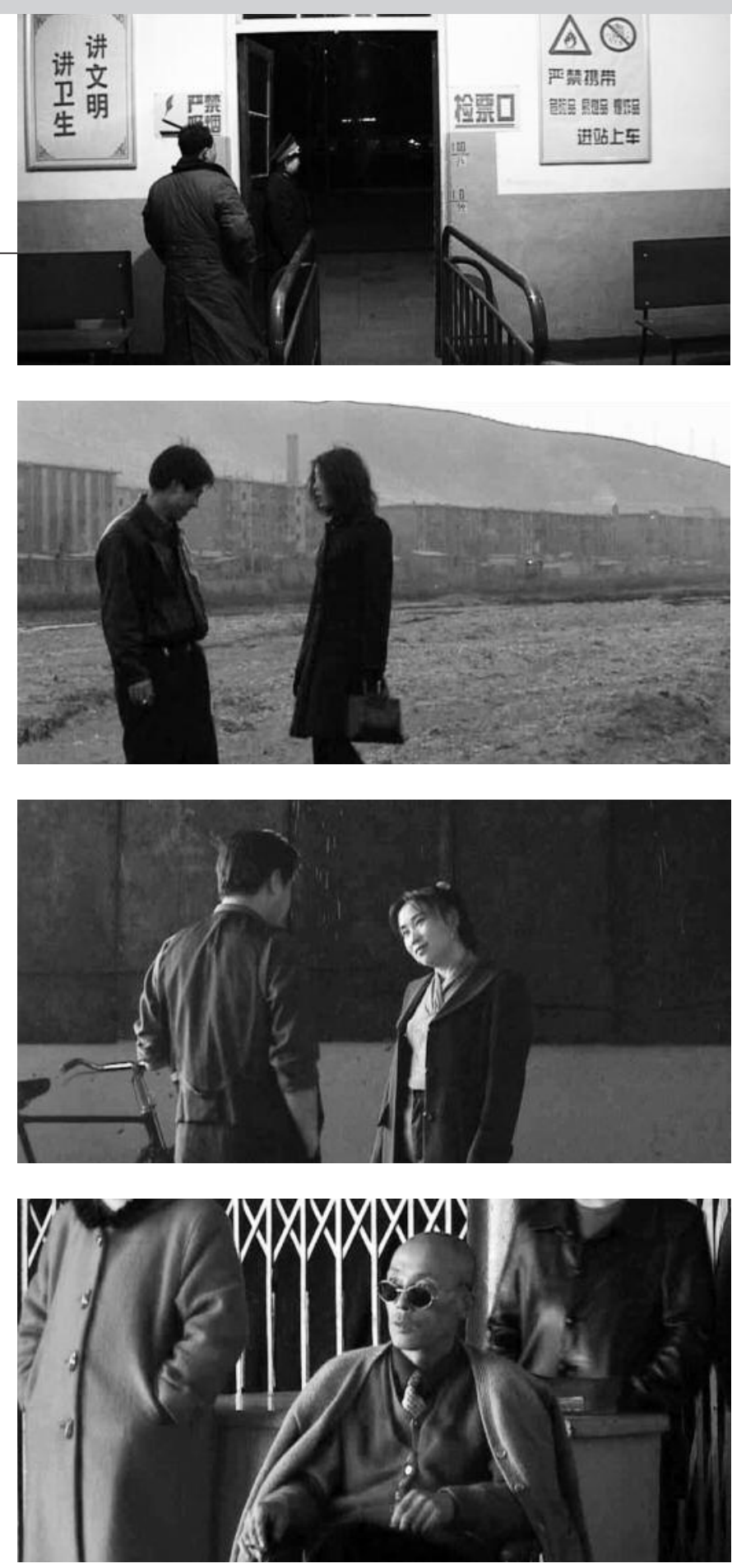

the observation of the persons who occupy the space, the depiction of their individual particularities and the relationships that bind them together, we can't grasp more than a vague sketch of their stories. The camera keeps a distance from the people; it doesn't try to interfere with them or to understand what is really going on. Instead, it attempts to capture the nature of personal interactions in public space. Jia Zhangke explained that he abandoned his former plan of carrying out interviews with clients of a sauna and decided instead to "[listen] to what the space is telling" and "then [...] have a dialogue with it" (II) following, as he claims, An-

10. Jia Zhangke, Jia Xiang 1996-2008: Jia Zhangke dianying shouji, Beijing, Beijing daxue chubanshe, 2009, p. 105 
(ת)

tonioni's words. The most striking element of this movie is indeed the relative silence in which the persons evolve. In all these public spaces, people meet and talk in a very reserved manner; we can only hear a few words, snatches of conversations, as if their speeches were muffled by the surroundings. The "voices are part of the environment, what they say is not important, what is important is what they look like" (12) and what space tells us. The fact that these people are in a public place inhibits them from openly displaying their interpersonal relationships; in turn, the filmmaker doesn't dare to approach them and disturb the mystery of the gazes and conversations. Both filmmaker and filmed subjects are restraining themselves, as if overwhelmed by a form of shyness or a sense of modesty due to the public nature of the space where they evolve. Public space is restrictive for the people as well as for the director, and forces the viewer to mobilise other faculties than the ones he normally uses in ordinary films: only his imagination can help him see beyond this spectacle of social constraints generated by space.

\section{space as a film character}

Some of these films are so much focused on the shooting place that space itself becomes the main character of the movie. Unlike mainstream documentaries, this kind of films focuses primarily on space instead of persons, events, or information. Such is West of the Tracks (Wang Bing, 2003), in which the factory crystallises the narration more than the people depicted in it. Many articles have discussed and described this film, ${ }^{(13)}$ so here I will just briefly synthesise the history of Shenyang factories. This huge industrial zone, situated in the north-eastern province of Liaoning, has had a continuous and eventful relationship with China's political and economic evolution throughout the twentieth century. Being successively a symbol of Japanese domination and then of the alliance with the Soviet Union, it later became an example of the achievement of industrialisation under Maoist rule, and served as a major source of employment for rusticated youths (zhiqing). The reform period finally heralded the end of the prominence of heavy industry and the necessary transition to economic responsibility for workers. The shooting of West of the Tracks starts in 1999 and records the progressive extinction of the living and working spaces of this zone. It ends in 2001, after the closing down of all the factories.

Wang Bing obviously treats the workers in an individual way - we know who they are and what they do, and they address the camera freely - but the factory itself is the real topic of
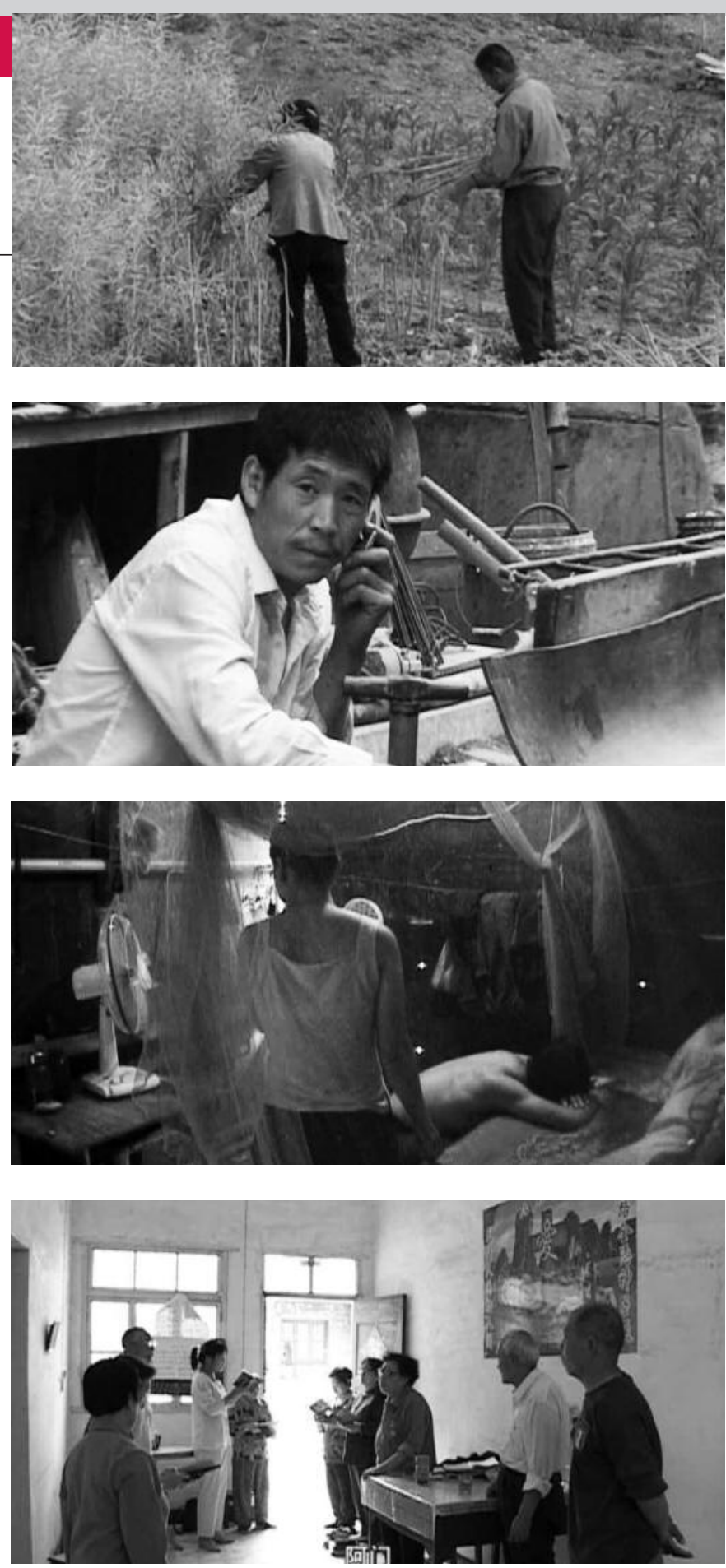

the film, and its dereliction is observed and described meticulously, even through the changes among the people who still live within it. The sequences on the workers testify to

11. Ibid., p. 106, see also in this issue Jia Zhangke, "In Public, in my own words".

12. Ibid., p. 106

13. Notably Lü Xinyu, “'Tiexiqu': Lishi yu jieji yishi” ('West of the Tracks': History and class consciousness), in Shuxie yu Zhebi, Guilin, Guangxi Normal University Press, 2008, pp. 3-20; Jie Li, "Wang Bing's West of the Tracks - Salvaging the Rubble of Utopia," Jump Cut: A Review of Contemporary Media, No. 50, Spring 2008 (accessible on http://www.ejumpcut.org/archive/jc50.2008/ WestofTracks/text.html, last accessed November 2009); Sebastian Veg, "From Documentary to Fiction and Back: Reality and Contingency in Wang Bing's and Jia Zhangke's Films," China Perspectives, No.3 (2007), pp. 141-149. See also my forthcoming paper "Cinéma et écriture de l'histoire: le cas des documentaires indépendants chinois," in Jean-Pierre Bertin-Maghit (ed.), Quand Clio s'empare du documentaire, Paris, INA L'Harmattan, 2010, or, for a concise version "Place et traitement de l'histoire dans les documentaires indépendants chinois," Monde chinois, №. 17 (2008), pp. 97-104. 


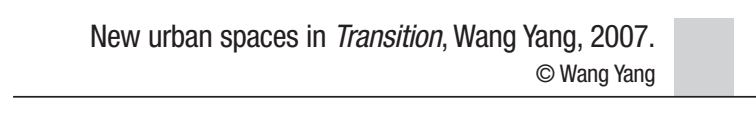

the factory's agony through individual stories, and reflect the loss of a once meaningful working and living place and its impact on people's life. Long tracking shots of the industrial landscape and the wandering of the filmmaker in the ruins of the living and working areas show the emphasis put on space and its cinematographic as well as historical characteristics. The history of the factory is neither explained through a text nor narrated by a voice. Apart from the chronology in the opening titles, the history of this place is conveyed by the observation of the architecture, the record of the closing down of the factories, and the polyphony of the workers conversations - in brief, by the portrayal of the many faces of the factory. Space - as in In Public or perhaps even better - becomes more eloquent than language itself.

The same focus on space exists in Transition (Dishang, Wang Yang, 2007), a more recent film that shows the modernisation of a suburb in X'an. This documentary is constructed as an exploration of the area that enfolds traditional rural villages and newly built public places (University campuses, residential buildings, and shopping malls). In the remaining rural areas, we observe ordinary life in the countryside: people harvesting, street vendors, and night activities (for instance open-air films screenings).

The new places aren't entirely finished yet, for some parts remain worksites and others are about to be dismantled for redevelopment. In this recently urbanised suburb, new public spaces stand next to places on the verge of becoming public, progressively extending their realm into the rural areas. Wang Yang describes the opening of a supermarket and the crowd entering to shop, while employees diligently fulfil their tasks. He also shows the huge empty spaces in front of the university where people come and go. Another sequence of the movie shows the rehearsal and training of staff working in a KTV.

Each "urban" scene alternates with a visual counterpoint in the "rural" area, thus creating a comparison between old public places - the agricultural villages - and new ones. Wang Yang shows the differences between being in public before, in rural areas, and now, in new spaces. In every public space, we see the same kind of distance between the people and the camera as in In Public. We usually don't hear the conversations well, and the camera doesn't try to interact with the people or disturb the action. However, here we are not only facing a softening of private behaviour in public space; in new spaces, it seems that everyone's personality is completely rubbed out, or at least neutralised, while in the agricultural villages, the camera manages to capture individual gazes and speeches. The waiters in the KTV are trained
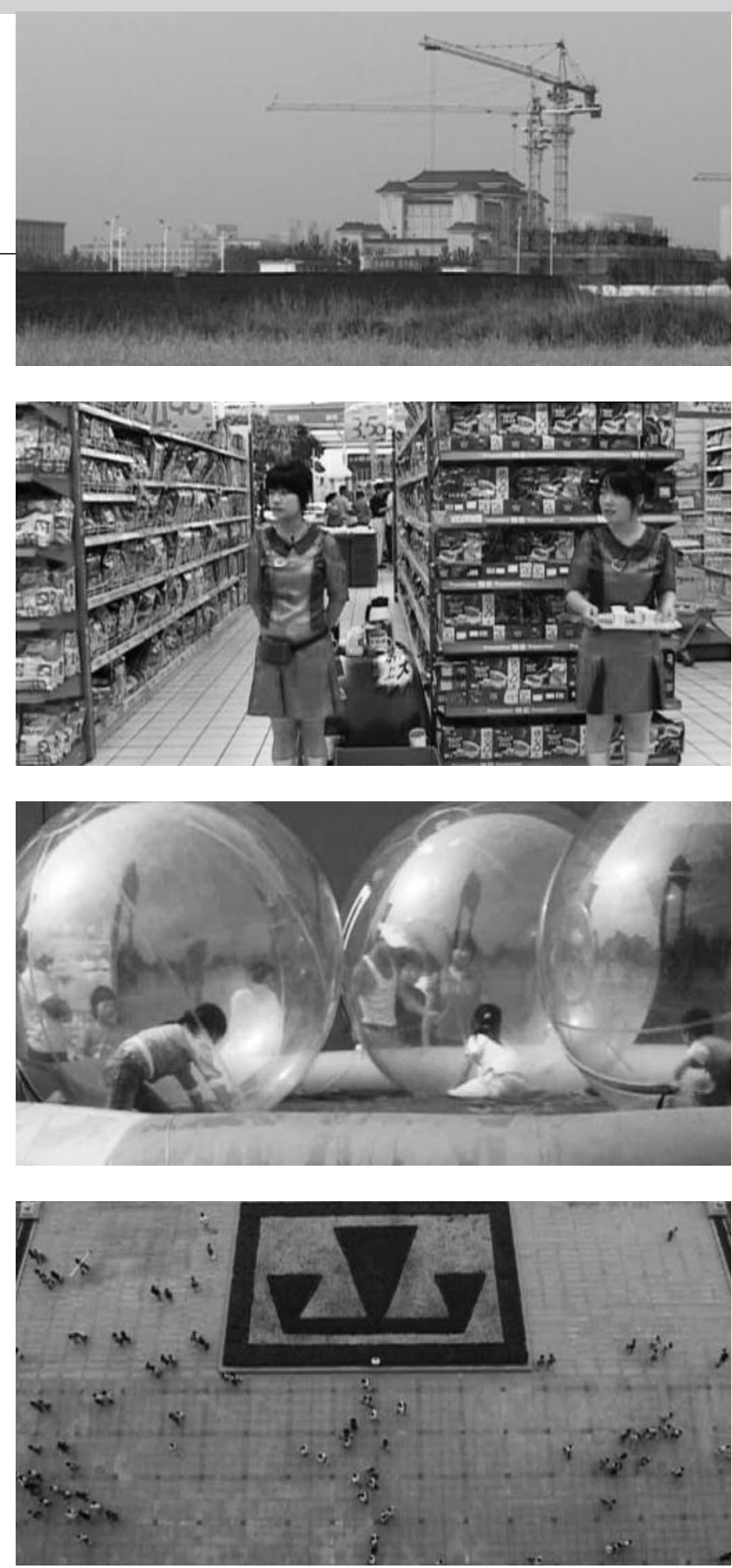

in a military way, they have to jog and march like soldiers, and everyone wears a kind of uniform. Behaviour becomes standardised: each gesture, each word is functional and measured. The contrast drawn with old public spaces serves to show how people's behaviour can be affected by a change of space.

Some elements in the movie even tend to present the new spaces as unreal, as if drawn out of a science fiction movie: the film starts with shots of cranes and construction sites accompanied by electronic music. As the camera changes angles and progressively descends from the elevated spaces to ground level, we have the feeling that a UFO is landing on a new territory. This comparison is followed, in the film, by the use of wide-angle shots showing crowds from the top, 
police doesn't really dissipate disorder, but rather creates an even more confusing situation sometimes. "Repetition," says Huang Weikai, ${ }^{(15)}$ "creates a feeling of absurdity," and this "absurdity" is the one we sense in media images that sometimes appear to be ceaseless replications of themselves. These typical media images, produced according to the conventions of visual journalism, are pulled out of the media realm where they would have been be separated, shortened, and used along with a commentary to explain their meanings. Here, Huang Weikai chooses to unite them in black and white and mix them together in order to emphasise their common features, and express an overall significance of public space as chaos. In Disorder, the artist expresses a critique of media images, their deprivation of meaning, as well as a reflection on the absurdity and cruelty of cities, where human life has sometimes no value at all. ${ }^{(16)}$ The blurred boundaries of spaces and the entanglement of the stories also express the fact that all the problems faced by urban populations are connected: poverty leads to madness, dishonesty, or desperation, and lack of confidence in justice to social unrest or suicide. Eventually, the "disorder" displayed and emphasised in this film is another way of making the audience reflect on cause and effect. As the Chinese title seems to imply, "(present) reality is the future of the past" (xianshi shi guoqu de weilai): the origins of the problems faced by our contemporaries have to be sought in a more or less recent history.

\section{Filmmaker, protagonist, and viewer relationships ${ }^{(17)}$ in Chinese independent documentaries}

As much as space shapes the form of these films, the filmmakers shape space and present it in a subjective manner. This reinterpretation is not only carried through editing, as in the case in Disorder, but also much earlier, starting with the shooting, when the director is physically involved in the situation and when he can infuse traces of his subjectivity into the images. Usually erased from the soundtrack - at least in the form of a commenting voiceover - the physical presence of the director is nonetheless very perceptible in the movies through the camera's movements. One of the characteristics of direct cinema is to allow filmmakers to expose the shooting apparatus in the movie as a proof of authenticity and subjectivity. The wobbling images transcribing experiences of space, and conversations with the protagonists showing the interaction between the filmed counterpart and the filmmaker are a part of this truth pact. The apparent standing back of the director expressed by the abandonment of the commenting voiceover is counterbalanced by his overwhelming presence behind the camera, sometimes mute or discreet - a mere body - but nonetheless very noticeable. His body, which helps the camera evolve within the space, is sometimes also visible in the frame, through his shadow, for instance. His relationship with the protagonists, often unveiled, makes him a genuine character in the movie, as much as the filmed counterpart.

Most of the independent documentaries don't show organised or prepared interviews but rather "free" conversations during which the protagonist shares his ideas, feelings, or memories, and often gets a response from the director. Filmmakers and filmed subjects have personal interactions during the shooting, and we usually see their relationship evolve as the movie unfolds. This interaction - whether it occurs in public or private places - creates another space within the one delimited by the frame, a space where the filmmaker and the filmed subject exchange ideas and glances and give the spectator a sense of ambivalent intimacy. This space is constituted of private interactions, but at the same time, the protagonists are aware of being filmed, and they know that what they share with the filmmaker is meant to be presented later to a public audience.

There is usually an agenda behind their speeches to the camera, and in several movies, the filmed subjects openly ask the director to "film this" or "that," in order to direct the public's awareness to something they find important, to something they believe is not taken enough into consideration by the media. This kind of sequence can be found in numerous movies, especially the ones with a strong critical content. The films of Ai Xiaoming, who uses a more activist approach of documentary, contain many such direct-to-camera addresses and gazes. In the above-mentioned Taishicun, villagers use the presence of the camera to testify to their injuries obtained during fights with their opponents. This method is directly related to Ai's concept of documentary filmmaking: in a 2007 interview, she explained that she actually tried to follow the protagonists' suggestions when film-

15. Interview carried out by email on 3 March 2009.

16. For instance, a story of a car crash that shows a man, probably badly injured in the accident, being discouraged from going to hospital by the responsible party and the police; or the sequence on the reactions of passers-by to an abandoned newborn on the street.

17. For a classic typology of the relationships between filmmaker and protagonists and the different "documentary gazes," see Bill Nichols, op. cit., pp. 76-105. For a discussion on spectator's space ("espace du spectateur"), see André Gardies, op. cit., pp. 176-213, and also Christian Metz, "Le signifiant imaginaire," Communications, No. 23 (1975), pp. $3-55$. 
ing, and considered herself "a volunteer to help them voice their opinions." ${ }^{(18)}$ This kind of sequence also appears in less overtly critical films: in West of the Tracks, an inhabitant of the factory's living area asks Wang Bing to film the demolition of his old compound. In both films, the device is used to prove that the protagonists are acknowledging the presence of the director and/or of a potential audience; that they are willing to be an active part of the filming process, and to testify to the public about their problems.

From the standpoint of the audience, direct-to-camera addresses imply a modification of the viewing process: the interactional space created by the relationship between filmed subject and film-maker then visibly and voluntarily incorporates a third part: the viewer, who feels personally concerned with the event on screen. Another larger space is thereby created, breaking the limit between the screening surface and the screening room, linking the film to its public. Hu Jie goes even further in In Search of Lin Zhao's Soul (Xunzhao Lin Zhao de Linghun). He has chosen to open this movie facing the camera, explaining to the audience why he became interested in Lin Zhao's experience and how this shooting has influenced his life. ${ }^{(19)}$ Whereas in the majority of fictional films, direct address to the spectator or to the director is usually avoided in order to protect the narrative flow, these documentaries integrate the existence of the viewer into the matter of the movie itself, as an acknowledgment of the third necessary member of the triumvirate that constitutes cinema: character, director, and public.

\section{An "experimentation in contact with the real": Filming/Map- ping}

Shot live, and based on the filmmaker's relationships and his confrontation with the real, Chinese independent documentary films use the unforeseen as filmic material. The importance of xianchang, or "on the spot realism (jishizhuyi)," ${ }^{(20)}$ has been one of the distinctive features of this movement, and has served, especially at the outset, to express a rejection of the television norms of documentary around a common practice of live shooting. This method allows the filmmakers to be in touch with reality: they let the events happen spontaneously instead of directing them by relying on a previously written script. As Wu Wenguang says about his own experience, to shoot a documentary, one has to "accept that life is unpredictable, and that's what makes the interest of our work." (2) Since the shooting must be a kind of "revelation" (22) instead of being a mere valida- tion of the director's opinions, the unexpected plays a strong role in his films, as well as in direct cinema documentaries in general. This unpredictable dimension of the shooting process stresses the importance of the director's personal experience of the situation. Just like performance artists who confront "real space" and "real people" with their work, and in this way welcome influences from the outside during the ephemeral presentation of their project, these film-makers rely on chance, the good will of the people, and space configuration. ${ }^{(23)}$

In this regard, these films are also a recording of the director's physical experience with the people, situation, and space of the movie. Each of these films contains on one side the narration evolving around the protagonists and the theme of the movie; and, indented on the other side, the subjective experience of the filmmaker with this reality. Both a recording and a construction, the film is the result of the confrontation of one person - the filmmaker - with reality, of his encounter with other persons and places that interact with him live, and of his freedom to discard or keep the fragile pieces of chance that constitute the footage. Besides

18. See "Ai Xiaoming, Caméra-stylo, pour un réquisitoire social," Monde Chinois No. 14 (October 2008), pp. 35-38.

19. I have translated and commented on this monologue in "Place et traitement de l'histoire dans les documentaires indépendants chinois," Monde chinois, №. 17 (2008), pp. 97104.

20. This expression is borrowed from Chris Berry and appears in "Facing Reality: Chinese Documentary, Chinese Postsocialism," in Wu Hung (ed.), Reinterpretation: A Decade of Experimental Chinese Art, Guangzhou, Guangdong Museum of Modern Art, 2002, pp. 121-131. This topic has also been discussed by Luke Robinson in "Contingency and Event in China's New Documentary Film Movement," 2007, Nottingham EPrints. (Unpublished paper), available at http://eprints.nottingham.ac. uk/546/ (last accessed 24 November 2009).

21. See my 2005 interview with Wu Wenguang in Beijing, published in "Wu Wenguang, filmer l'imprévisible," Monde chinois, No. 14 (October 2008), pp. 28-34.

22. Ibid., p. 30.

23. I believe, together with other scholars, that there is a strong link between performance art and the history and practice of independent documentary films in China. See Bérénice Reynaud, "Dancing with Myself, Drifting with my Camera: The Emotional Vagabonds of China's new Documentary," Senses of cinema, No. 28 (September-0ctober 2003), available at http://archive.sensesofcinema.com/contents/03/ 28/chinas_new_documentary.html (last visited March 2006), and Charles Leary, "Performing the Documentary, or Making It To the Other Bank," Senses of cinema, No. 27 (July-August 2003), available at http://archive.sensesofcinema.com/contents /03/27/performing_documentary.html (last visited March 2006).

24. See Luke Robinson, op. cit., p. 1 .

25. Such as Valerie Jaffee, "Every Man is a Star: The Ambivalent Cult of Amateur Art in New Chinese Documentary Movement" (pp. 77-108), and Matthew David Johnson, "Wu Wenguang and the New Documentary Cinema's Politics of Independence" (pp. 47-76), both in Paul Pickowicz and Zhang Yingjin (eds.), From Underground to Independent: Alternative Film Culture in Contemporary China, Lanham, Rowman \& Littlefield, 2006; see also Wang Yiman, "The Amateur's Lightning Rod: DV Documentary in Postsocialist China," Film Quarterly, Vol. 58, No. 4 (2005), pp. 16-26. See also Jia Zhangke's essay, "The Age of Amateur Cinema Will Return" ("Yeyu dianying shidai jijiang zaici daolai"), in Zhang Xianmin and Zhang Yaxuan (eds.), Yigeren de yingxiang: DV wanquan shouce, Beijing, Zhongguo qingnian chubanshe, 2003, pp. 307-308. 
being a proof of authenticity, a way to convey "greater audience engagement as a consequence of a necessarily ambiguous aesthetic," ${ }^{(24)}$ and/or an emphasis on amateur aesthetics as noted by many researchers, ${ }^{(25)}$ the prominence of live shooting and the permeability of the film to the unforeseen are also a way to creatively braid together subjective experience and the recording of an uncontrollable external reality. The acknowledgement of the influence of the filmmaker on reality, and the interplay between the two of them perceptible in these films, leads to the creation of something more than an attempt to replicate reality "as it is" (world minus camera) and goes beyond the informative goals of mainstream documentaries. The most visible manifestations of this method are sequences breaking away from the viewers', filmmakers', and filmed subjects' expectations of reality, sequences so fortuitous that they appear unlikely to all three. Some of these scenes are quite famous and have been discussed elsewhere, such as that in Wu Wenguang's Bumming in Beijing (Liulang Beijing, 1990) in which the painter Zhang Xiaping has a nervous breakdown, ${ }^{(26)}$ or when the closing down of the zinc plant is announced "live" to the workers and the filmmaker in West of the Tracks. ${ }^{(27)}$ Contingency, allied with the ability of the filmmaker to meaningfully capture its apparition, creates on-screen sequences breaking away from the documentary's required role, scenes in which "reality surpasses fiction." In West of the Tracks again, the sequence in which Du Yang reviews his family pictures, waiting anxiously for news of his detained father, ends when Time bursts onto the scene in the form of the sudden ringing of a clock. This sound surprises both $\mathrm{Du}$ Yang and Wang Bing - the first absorbed in his own pain and memories, the other in the spectacle of the tears of the young man. The camera is distracted for an instant from the face of Du Yang and quickly reaches the wall where the sound originates, as if to verify the existence of the clock. In an allegorical manner, this short passage gives shape to exactly what the protagonist is experiencing: time's slowness during an endless waiting, and simultaneously, its irremediable and rapid fading away, as Du Yang looks at images of his family's past. This sudden clock-ringing ruptures the narrative of the son and the father, and brings the film to another level of meaning: the viewer can't help but link Du Yang's situation to a more universal meditation on time and history. Deleuze and Guattari might say these films function as "maps" in the sense that they are "entirely oriented toward an experimentation in contact with the real." ${ }^{(28)}$ Referring principally to literature and to the relationship between the world and the activity of writing, both thinkers make a dis-


tinction between books that work as a "tracing" of reality and whose function is to reproduce, and those that form a

26. See Chris Berry, op. cit., p. 125.

27. See Luke Robinson, op. cit., pp. 23-24.

28. Gilles Deleuze, Felix Guattari, $A$ Thousand Plateaus: Capitalism and Schizophrenia, London, Athlone Press, 1988, p. 12. 
"map" of the world. The latter implies a confrontation with reality, its "deterritorialisation" through a form of creation, and finally leads to the drawing of "lines of flight" in our apprehension of the world. Transposed into cinema, the distinction between "tracings" and "maps" can be useful as a parallel to distinguish in this case television/mainstream documentaries from independent ones. "The map has to do with performance, whereas the tracing involves an alleged "competence," say Deleuze and Guattari. ${ }^{(29)}$ This can reflect the contrast between the educational or informational function of TV documentaries and the subjective work of recording reality in Chinese independent documentaries. We have already mentioned that the importance of contingency and of the filmmaker's physical implication with the world was close to some characteristics of performance art. This, combined with the absence of purely informative goals and the rejection of newsreel formats, brings these films closer to the deleuzian definition of mapping. The "tracing (...) always goes back to the same" for both philosophers, whereas the map "has multiple entryways"; ${ }^{(30)}$ hence the possibility for various interpretations and usage of these films, which contain many ambivalent situations and complex characters, and try to avoid media conventions. Whereas mainstream documentaries try to report, explain, and reproduce the world and are subject to strict conventions, independent documentaries interpret reality in a creative way, even if they may seem to move away from it in the process. The unforeseen sequences described earlier can be seen as the visible manifestations of a "line of flight," for they are moments escaping the logic of plain reality, allowing the film to access another dimension of meaning.

\section{Circulation}

To conclude, I would like to raise the question of the dissemination of these films and the position of this movement in China's cinematographic landscape. The space where movies circulate and are shown greatly influences their reception and conditions their nature. The status of the screening spaces gives them a certain identity, even if it can evolve according to the development of this cinematography. Characterising and defining the sphere where Chinese independent cinema belongs, and discussing the legitimacy to use one term or another to name it, is a task many researchers have tried to fulfill. Questions on the nature of "independence" or "underground" cinema in China are often related to questions of space: "inside" or "outside" the system, "marginal," "mainstream," and "urban generation" are terms that attempt to define the specificities of this - once private - alternative cinema culture and the relationship it entertains with public institutions. ${ }^{(31)}$

The first independent documentaries were indeed made by individuals linked to television stations, who could use their facilities (cameras and editing rooms), but whose personal projects remained largely outside the television realm. They were shown at home among friends and fellow directors but stayed invisible to a broader audience, except for some overseas screenings. A certain number of organisations specialised in promoting and showing these movies appeared in the last decade, providing screening and discussion spaces to this parallel cinematography, while aiming at the development of a specific audience. To name just a few: the Nanjing Independent Film Festival, Yunfest, Caochangdi Workstation, Fanhall Films, and Iberia. ${ }^{(32)}$ Nowadays, even if the movies still don't exist for national cinema institutions, they do live in parallel structures, thanks to these new spaces. The very existence of these spaces and their rapid growth indicate an increasing plurality in Chinese film production, as well as in film distribution: there are now different places and ways to enjoy different kinds of movies. From the private spaces where they were previously sequestered, the movies have migrated to a new cinematographic realm, often situated in suburban art spaces of Chinese cities, but also in University spaces, where they form an enclave in the institutions. This "buffer zone," which extends the territory of cinema, protects and allows these films to exist, but at the same time can neutralise them by dragging them into the limbo of amateurism. Since they are not part of Chinese cinematographic institutions, these films and their authors are not recognised as professionals, and this lack of status also weakens the range of their discourse. Moreover, as these films address important public subject matter, such as rural politics, migrant workers, or the conditions of the elderly, their nonvisibility to a large audience exacerbates the absurdity of

29. Ibid., p. 13.

30. Ibid., p. 12.

31. See in particular Lü Xinyu, Jilu Zhongguo (Recording China), Beijing, Sanlian shudian, 2003; Zhang Zhen, The Urban Generation: Chinese Cinema and Society at the Turn of the Twenty-first Century, Durham, Duke University Press, 2007, Paul Pickowicz and Zhang Yingjin (eds.), From Underground to Independent: Alternative Film Culture in Contemporary China, Lanham, Rowman \& Littlefield, 2006, and Chris Berry, Postsocialist Cinema in post-Mao China: The Cultural Revolution after the Cultural Revolution, New York, Routledge, 2004

32. For a study on alternative cinema cafés, see Seio Nakajima, "Film Clubs in Beijing," in Paul Pickowicz and Zhang Yingjin (eds.), op. cit., pp. 161-188; for a history of their apparition, see Zhang Yaxuan, "Wuxian de yingxiang" (Unlimited Images), Movie and Television Art, No. 3 (2004), pp. 17-23. 
their situation. Since the definition of cinema as a show is the encounter of moving images with a public in a dedicated space, the fact they have a hard time reaching an audience and that they are not shown in proper institutionalised movie theaters could even drive them further away from being a true cinematography, while their aim is precisely to change the conception of documentary from a mainstream visual report to a real cinematographic work.

Independent cinema was labeled "underground" in China when the films' theatrical release was forbidden on national territory and when they could only circulate in the private sphere. Now that it no longer depends on institutional production and contributes to the rise of an alternative culture through these new spaces and modes of circulation, independent cinema is more and more defined as belonging to the minjian ${ }^{(3)}$ sphere, along with other cultural and intellectual activities. Lü Xinyu said about this movement that it appeared "both inside and outside of the system," ${ }^{\left({ }^{44}\right)}$ the first independent documentarists being strongly linked to television channels, but also to avant-garde art circles.

We could go further by saying that this new cinematographic realm isn't in fact completely separated from the rest of the institutions, or that this distinction between inside and outside isn't that frozen in most cases: independent cinema indeed entertains complex relationships with the institutions, being their critical extension as well as an escape from them. Prolonging Chris Berry's reading ${ }^{(35)}$ of Deleuze and Guattari, we consider the concept of rhizome a daring but useful model for the relationships between Chinese cinema, television institutions, and independent cinema. In A Thousand Plateaus, the philosophers explain:

Every rhizome contains lines of segmentarities according to which it is stratified, territorialised, organised, signified, attributed, etc., as well as lines of deterritorialisation down which it constantly flees. There is a rupture in the rhizome whenever segmentarity lines explode into a line of flight, but the line of flight is part of the rhizome. ${ }^{(36)}$

In other words, a rhizome is a system that contains a principle of organisation and constraint, but also the possibility for a principle of chaos to exist and allow some elements to escape from it and pursue an "aparallel evolution" ${ }^{(37)}$ with the rest of the rhizome. The national cinema and television system in China represents the former principle, while independent films, by moving cinema practice away from its institutionalised territory to the minjian realm, is an image of the latter. There is no binary opposition between the inside of the system and the outside, since both communicate in some ways through mutual assistance, exchange, borrowing, imitation, or conflict. Independent filmmakers often keep an activity within the audiovisual system and contribute directly or indirectly to shaping it. Their films are sometimes "reterritorialised" when they are shown on TV channels, or when they reach national cinematographic distribution, as in the case of Jia Zhangke. The involvement of some directors in other fields of society (activism, journalism, research, etc.) also ensures the ties of this cinematography with other institutional or para-institutional domains, and the blurring of stark limits and contrasts between the "independent," minjian, and "official" spheres.

Chris Berry discussed in a quite similar way the role of cinema in "postsocialist China." Referring to and reflecting on a precise corpus of films shot in the aftermath of the $\mathrm{Cul}$ tural Revolution (1976-1981), he used the concept of rhizome to define the way cinema "as a social institution" (38) was, at that time, "the possibility of conceiving of and discursively articulating differences." ${ }^{(39)}$ For him, these films constituted "areas or zones that work against the repressive structures of an order to open up differences and heterogeneity." (40) This reference to A Thousand Plateaus was mobilised to distinguish the role of cinema in China from the one it is believed to have in the West: an alternative public sphere, guaranteed by the existence of capitalist pluralism. For Berry, Chinese cinema wasn't able at that time to take up the role of an alternative public sphere, but it would still provide, through cinematographic means, a possibility for pluralism to be expressed. One of the differences between his analysis and mine lies in the fact that I refer to independent cinema at the turn of the twenty-first century, whereas older "official" films constitute Berry's corpus. While I agree

33. This word, literally translatable as "among the people" or "popular," signifies also "nonofficial" or "non-governmental." It characterises a wide range of activities (economic, as well as artistic, cultural...) that don't belong to or depend on the state. These activities can be carried out in public, but they don't rely primarily on public institutions and initiatives to exist. For further readings, see Michel Bonnin and Yves Chevrier, "The Intellectual and the State: Social Dynamics of Intellectual Autonomy During the Post-Mao Era," The China Quarterly, No. 127 (1991), pp. 569-593, and Gordon White, "The Dynamics of Civil Society in Post-Mao China," in Brian Hook (ed.), The Individual and the State in China, Oxford, Clarendon Press, 1996, pp. 196-222.

34. Lü Xinyu. op. cit., p. 16

35. In Postsocialist Cinema in Post-Mao China: the Cultural Revolution after the Cultural Revolution, New York, Routledge, 2004; see the discussion below.

36. Gilles Deleuze, Felix Guattari, op. cit., p. 9.

37. Ibid., p. 10.

38. Chris Berry, op. cit., p. 20

39. Ibid., p. 20.

40. Ibid., p. 20 
with Berry that Chinese films - independent or not - can take an important role as carriers of "heterogeneities," I also argue that the rhizomatic nature of independent cinema lies not only in the films' production of meaning but also in their mode of production and circulation, as well as in their status vis-à-vis the institutions. The concept of the rhizome is also, to my mind, a way to define the position of this independent cinematography vis-à-vis the institutions, and a good metaphor of the bonds that unite them together. The practice of independent documentary filmmaking, closer to a form of mapping than to "official" tracings of the world, could only create a "line of flight" in the rhizome of cine- matographic institutions and join the minjian realm. This unconventional way of showing reality, born on the outskirts of the institutional audiovisual system and deprived of official recognition, had somehow to find adequate means to display itself to the public. By founding their own cinematic realm progressively, these filmmakers have deterritorialised documentary film by moving their production and distribution from state-owned television channels to the minjian sphere. As these films have given birth to a new form of aesthetics in Chinese documentaries, they have also had to produce new forms of dissemination, since they were not meant to be part of existing cinematographic institutions. •

\section{Glossary}

Ai Xiaoming 艾曉明

Bakuo Nanjie 16 hao 八廓南街16號

Cao Fei 曹斐

Chen Xinzhong 陳新中

Cunmin Jilupian 村民紀錄片

Dingzi 釷子

Dishang 地上

Duan Jinchuan 段錦川

Gongbu de Xingfu Shenghuo 貢布的幸福生活

Gonggong Changsuo 公共場所

He Mingong Tiaowu 和民工跳舞

Houjie 厚街

Hu Jie 胡傑

Huang Weikai 黄偉凱

hukou 户口

Ji Dan 季丹

Jia Kai 賈愷

Jia Zhangke 賈樟柯

Jiang Zhi 蔣志

Jianghu 江湖

jishizhuyi 紀實主意

Kong Cheng yi Meng 空城一夢

Laotou 老頭

Li Xiaofeng 黎小锋

Lin Xin 林釒

Liulang Beijing 流浪北京

liumang 流讯

mangliu yishujia 盲流藝術家

Meishi Jie 煤市街

Minjian 民間
Ni de Mingzi Jiao Waidiren 你的名字叫外地人

Ning Ying 寧瀛

Ou Ning 歐寧

Renao 熱鬧

Sanlidong 三里洞

Sha Qing 沙青

Shangfang 上訪

Si Hai wei Jia 四海為家

Taishicun 太石村

Tiexiqu 鐵西區

Waimian 外面

Wang Bing 王兵

Wang Wo 王我

Wang Yang 王楊

Wo de Cunzi 2007 Nian 我的村子2007年

Wo Zuihou de Mimi 我最後的秘密

Wu Wenguang 吴文光

xianchang 現場

Xiangdui 相對

Xianshi shi Guoqu de Weilai 現實是過去的未來

Xiwang zhi Lü 希望之旅

Xunzhao Lin Zhao de Linghun 寻找林昭的靈魂

Yang Lina (Yang Tianyi) 楊荔鈉 (楊天乙)

Zha Qiao 炸橋

Zhang Jinli 張金利

Zhang Yi 張一

Zhao Liang 趙亮

zhiqing 知青

Zhou Hao 周浩 